\title{
Fine Needle Aspiration Cytology in Palpable Breast Lumps: A Retrospective Study
}

\author{
Poonam Sharma $^{1 *}$, Mehnaz Choudhary ${ }^{2}$, Sonika Gupta $^{3}$, Subhash Bharadwaj $^{4}$ \\ ${ }^{1}$ Lecturer, Department of Pathology, Government Medical College, Jammu Kashmir, India \\ ${ }^{2}$ Demonstrator, Department of Pathology, Government Medical College, Jammu Kashmir, India \\ ${ }^{3}$ Consultant Gynaecologist, District Hospital, Udhampur, India \\ ${ }^{4}$ Professor and Head, Department of Pathology, Government Medical College, Jammu Kashmir, India
}

\begin{abstract}
DOI: $\underline{10.36348 / \mathrm{sipm} .2020 . \mathrm{v} 05 \mathrm{i} 02.016}$
| Received: 18.02.2020 | Accepted: 25.02.2020 | Published: 29.02.2020

*Corresponding author: Poonam Sharma
\end{abstract}

\section{Abstract}

Background: Breast lumps are a common presentation among females. Breast carcinoma is $2^{\text {nd }}$ commonest malignancy in females in India and needs early detection for proper management. Fine needle aspiration cytology (FNAC) is an established and highly accurate method in the investigation of palpable breast lumps. So the study was performed to analyse the cytomorphological spectrum of palpable breast lesions in a Tertiary Care Centre in North India. Material and Methods: This retrospective study was carried out in the Department of Pathology in GMC, Jammu. Female patients with suspected breast lumps who underwent FNAC in our department over a period of one year were included in the study. Detailed history including patient's age, site and duration of breast lumps was noted. Findings of FNAC were recorded in detail and results tabulated. Results: Inadequate/Non-Diagnostic aspirations were seen in 13 cases. Majority of cases were seen in $4^{\text {th }}$ decade of life. Among all aspirations, fibroadenoma was the commonest lesion seen in $36.4 \%$ cases while malignancy was seen in $20.1 \%$ cases. Conclusions: FNAC is a rapid, economical, and reliable tool for the diagnosis of palpable breast lesions. FNAC provides useful information in the management of the lesions and prevents unnecessary surgery in cases of non-neoplastic lesions.

Keywords: Cytology; Breast; Neoplasm; Malignancy.

Copyright @ 2020: This is an open-access article distributed under the terms of the Creative Commons Attribution license which permits unrestricted use, distribution, and reproduction in any medium for non-commercial use (NonCommercial, or CC-BY-NC) provided the original author and sources are credited.

\section{INTRODUCTION}

Breast lump is the commonest presentation in most of the breast diseases. Breast cancer is the $2^{\text {nd }}$ commonest cancer among women in India [1]. Majority of the breast lumps observed in general population are benign [2]. FNAC of breast lumps is a highly sensitive, easy and cost effective procedure that can be carried out at outpatient department $[3,4]$. It is a rapid and reliable procedure and helps in planning of treatment in the breast lump [5]. FNAC can prevent unnecessary surgery and could provide a diagnosis with only 10$30 \%$ of the cost of surgical biopsy. Molecular ancillary techniques, i.e., progesterone receptor and oestrogen receptor and DNA pattern analysis can also be performed on aspirated material. Diagnostic accuracy of the FNAC can be increased by multiple sampling of appropriate sites by ultrasonography guidance and/or mammographic localization [6]. The present study was performed to evaluate the spectrum and distribution of palpable breast lumps on FNAC.

\section{MATERIAL AND METHODS}

This retrospective study was conducted for a period of 1 year in cytology section of Post Graduate Department of Pathology, GMC Jammu from January 2017 to December 2017. All the patients with suspected breast lumps who underwent FNAC in our Department were included. The study was approved by institution ethics committee. The clinical data pertaining to patient's age, sex and site were recorded from the requisition forms and data registers. All the aspirations were performed by cytopathologists using 22-24G needles attached to $10 \mathrm{cc}$ disposable syringe. One to two passes were given and the aspirated material was smeared onto glass slides. Smears were fixed in $95 \%$ ethyl alcohol and stained with Papanicolaou stain. Giemsa stain was done on air dried smears. ZiehlNeelson (ZN) staining was done whenever a cytological diagnosis of granulomatous disease was made. In cases where fluid was aspirated on FNA, the fluid was centrifuged and smears were prepared from the sediment followed by the above staining methods.. The stained FNA smears were examined by two 
cytopathologists independently for cytomorphological findings, diagnosis and differential diagnosis where needed.

\section{RESULTS}

FNAC was performed in 184 cases which showed age range of 12-78 years. Majority of females were seen in $4^{\text {th }}$ decade of life followed by $5^{\text {th }}$ decade. Aspirations in 13 cases were reported as unsatisfactory due to scant cellularity and repeat aspiration advised. Wide varieties of lesion were seen which included inflammatory, benign and malignant lesions. Benign neoplasms were seen in majority of cases (38.0\%) followed by malignancy $(20.1 \%)$ (Table 1$)$. Benign breast disease not otherwise specified (NOS) were seen in $10.9 \%$ cases while inflammatory lesions were seen in $9.2 \%$ cases. Benign cystic lesions were seen in $9.8 \%$ cases and benign proliferative disorders in $4.9 \%$ cases (Table 1).

Fibroadenoma was the commonest benign neoplasm $(36.4 \%)$ in our study. Of these, cellular fibroadenoma was seen in 4 cases while fibroadenomatosis was seen in 2 cases. Infiltrating duct carcinoma NOS was the commonest malignant breast tumour in the present study $(17.9 \%)$ followed by DCIS $(1.1 \%)$. Solitary case of mucinous and lobular carcinoma was also seen in our study.

Table-1: Distribution of Breast Lesions on FNAC

\begin{tabular}{|c|l|c|c|}
\hline FNAC & & Number & Percentage \\
\hline Inflammatory & 1. Abscess & 9 & 4.9 \\
& 2. Acute Mastitis & 4 & 2.2 \\
& 3. Fat Necrosis & 2 & 1.1 \\
& 3. Granulomatous Mastitis & 1 & 0.5 \\
& 5. Periductal Mastitis & 1 & 0.5 \\
\hline Benign Breast Disease NOS & & 20 & 10.9 \\
\hline Benign Proliferative & 1. Fibrocystic Change & 8 & 4.3 \\
Disorders & 2. Duct Ectasia & 1 & 0.5 \\
\hline Benign Cystic Leisons & 1. Simple Cyst & 9 & 4.9 \\
& 2. Galactocele & 8 & 4.3 \\
& 3. Mucinous Cyst & 1 & 0.5 \\
\hline Benign Neoplams & 1. Fibroadenoma & 67 & 3.4 \\
& 2. Lipoma & 1 & 1.1 \\
& 3. Papilloma & 33 & 0.5 \\
\hline Malignant & 1. Infiltrating Ductal Carcinoma NOS & 2 & 17.9 \\
& 2. DCIS & 1 & 0.5 \\
\hline Inadequate Aspiratons & 3. Mucinous Carcinoma & 1 & 0.5 \\
\hline Total & 4. Lobular Carcinoma & 13 & 7.1 \\
\hline
\end{tabular}

\section{DISCUSSION}

Breast lumps are common presentation in surgery and gynaecology outpatient department. There is increasing awareness and the associated anxiety and stress among women which compels the patients to seek medical advice [7]. FNAC of breast lumps is an important part of triple assessment (clinical examination, imaging, and FNAC) of palpable breast lumps. It is a simple, cost effective and less traumatic as well as highly sensitive and specific method for assessment of breast lumps [7].

Age range of patients in our study was 12-78 years. Similar results were also obtained in previous studies [8, 9]. Dennison G et al. [10] from UK observed an age range of 18-92 years likely due to higher life expectancy in UK as compared to Asia and Africa. Majority of cases were seen in $4^{\text {th }}$ decade followed by $5^{\text {th }}$ decade of life. Mane PS et al. [7] also observed maximum cases in $4^{\text {th }}$ decade of life. Benign neoplasm were the commonest lesions in our study seen in $38.0 \%$ cases, similar to findings of study done by Bukhari $\mathrm{MH}$ et al. [9], Rocha PD et al. [11] and Feichter GE et al. [12]. Malignant lesions were seen in $20.1 \%$ cases in our study similar to previous studies $[9,13]$.

Fibroadenoma was the commonest lesion $(36.4 \%)$ in this study. Most studies have found fibroadenoma to be most common lesion [5, 7, 15]. Among malignant lesions, majority of the cases were infiltrating ductal carcinoma with two cases of DCIS and solitary case each of lobular carcinoma and mucnious carcinoma. Binayke $\mathrm{R}$ et al. [14] in their study observed ductal carcinoma in all the malignant aspirates. Qasim M et al. [13] also observed invasive ductal carcinoma as the most common malignant lesion in their study.

20 cases of benign breast disease NOS were also seen in our study. Among the inflammatory category of breast lesions, we observed 9 cases of breast abscess, 4 cases of acute mastitis and 2 cases of fat necrosis. One case each of Granulomatous mastitis 
was also seen with presence of caseating granulomas and was positive for acid fast bacilli on $\mathrm{ZN}$ stain. 9 cases of simple cyst and 8 cases each of Galactocele and Fibrocystic disease were also seen in our study.

\section{CONCLUSIONS}

The study highlights the role of FNAC as a rapid, economical, and reliable tool for the diagnosis of palpable breast lesions. Fibroadenoma was the commonest lesion in this study while Malignancy was the second commonest lesion. Adequate sampling, high quality smear preparation and experienced cytopathologist can diagnose majority of non-neoplastic and neoplastic conditions on FNAC.

\section{REFERENCES}

1. Sandhu, D.S., Sandhu, S., Karwasra, R.K., Marwah, S.(2010). Profile of breast cancer patients at a tertiary care hospital in North India. Indian $J$ Cancer, 47(1):16-22.

2. Cochrane, R.A., Singhal, H., Monypenny, I.J., Webster, D.J., Lyons, K., Mansel, R.E. (1997). Evaluation of general practitioner referrals to a specialist breast clinic according to the UK national guidelines. Eur J Surg Oncol, Jun;23(3):198-201.

3. Rimm, D.L., Stastny, J.F., Rimm, E.B., Ayer, S., Frable, W.J.(1997). Comparison of the costs of fine-needle aspiration and open surgical biopsy as methods for obtaining a pathologic diagnosis. Cancer, 25;81(1):51-6.

4. Silverman, J.F., Lannin, D.R., O’Brien, K., Norris, H.T.(1987). The triage role of fine needle aspiration biopsy of palpable breast masses. Diagnostic accuracy and cost-effectiveness. Acta Cytol, 31(6):731-6.

5. Badge, S.A., Ovhal, A.G., Azad, K., Meshram, A.T.(2017). Study of Fine-Needle Aspiration Cytology of Breast Lumps in Rural Area of Bastar
District, Chhattisgarh. Med J DY Patil Univ. 2017;10(4):339-42.

6. Rathod, G.B., Goyal, R., Bhimani, R.K., Goswami, S.S.(2014). Metaplastic carcinoma of breast in 65 years old female - A case report. Med Sci, 10(39):77-81.

7. Tiwari, M. (2007). Role of fine needle aspiration cytology in diagnosis of breast lumps. Kathmandu Univ Med J (KUMJ), Apr-Jun;5(2):215-7.

8. Ahmed, H.G., Ali, A.S., Almobarak, A.O.(2009). Utility of fine-needle aspiration as a diagnostic technique in breast lumps. Diagn Cytopathol, 37(12):881-4.

9. Bukhari, M.H., Arshad, M., Jamal, S., Niazi, S., Bashir, S., Bakhshi, I.M. (2011). Use of fineneedle aspiration in the evaluation of breast lumps. Patholog Res Int. 2011:689521.

10. Dennison, G., Anand, R., Makar, S.H., Pain, J.A.(2003). A prospective study of the use of fineneedle aspiration cytology and core biopsy in the diagnosis of breast cancer. Breast J, 9(6):491-3.

11. Rocha, P.D., Nadkarni, N.S., Menezes, S. (1997). Fine needle aspiration biopsy of breast lesions and histopathologic correlation. An analysis of 837 cases in four years. Acta Cytol, 41(3):705-12.

12. Feichter, G.E., Haberthur, F., Gobat, S., Dalquen, P.(1997). Breast cytology. Statistical analysis and cytohistologic correlations. Acta Cytol, 41(2):32732.

13. Qasim, M., Ali, J., Akbar, S.A., Mustafa, S. (2009). Lump breast: Role of FNAC in diagnosis. Prof Med J, 16:235-8.

14. Binayke, R., Dhage, S., Amberkar, M., Costa, G.D. (2018). Cytomorphological spectrum of breast lesions diagnosed by fine needle aspiration cytology. Int. J. Med. Health Res, 4(8):168-71.

15. Bell, D.A., Hajdu, S.I., Urban, J.A., Gaston, J.P. (1983). Role of aspiration cytology in the diagnosis and management of mammary lesions in office practice. Cancer. Apr 1;51(7):1182-9. 